\title{
Dotação física e talento esportivo: investigações acadêmicas na educação infantil
}

https://doi.org/10.11606/issn.1981-4690.v35inespp23-30

\author{
Carlos Samuel Rossi* \\ Rosemeire de Araújo Rangni*
}

*Universidade Federal

de São Carlos,

São Carlos, SP, Brasil.

\begin{abstract}
Resumo
A dotação física e o talento esportivo se manifestam nesse modelo por desempenhar papel significativo no grande conjunto de influências das habilidades físicas naturais unidas às competências treináveis dadas pelo processo desenvolvimentista proporcionado pelo ambiente. 0 referencial foi o Differentiated Model of Giftedness and Talent (DMGT), de Gagné. Assim, o objetivo geral foi investigar a interface Dotação e Talento e Educação Física na Educação Infantil. A metodologia empregada foi a pesquisa bibliográfica de natureza qualitativa. Foram buscados trabalhos acadêmicos em dois bancos de dados: Biblioteca Digital Brasileira de Teses e Dissertações (BDTD) e Scientific Eletronic Library Online (SciELO), com recorte temporal de cinco anos. Os resultados obtidos foram quatro produções encontradas: uma tese e três dissertações defendidas nos anos de 2017 e 2019. Concluiu-se que há poucas pesquisas que abordem especificamente a dotação física e talento esportivo na Educação Infantil, sendo que as produções encontradas versam sobre outros niveis de ensino. Isso ressalta a importância de se olhar para as crianças dotadas e talentosas desde o início do percurso educacional.
\end{abstract}

Palavras-chave: Dotação; Talento; Educação Física; Educação Infantil.

\section{Introdução}

A legislação educacional brasileira vigente aponta que estudantes com altas habilidades ou superdotação são públicos da Educação Especial ${ }^{1}$. A Resolução $n^{\circ} 04$, de $2009^{2}$, define que esses estudantes são:

III - [...] aqueles que apresentam um potencial elevado e grande envolvimento com as áreas do conhecimento humano, isoladas ou combinadas: intelectual, liderança, psicomotora, artes e criatividade ${ }^{2}$.

Autores $^{3}$ assinalam estudos que demonstram o senso comum existente no sistema educativo que permeia os mitos sobre esse tema, pois sempre é esperado que alunos acima da média sejam melhores e se destacam ou que têm os altos desempenhos e notas, fatores esses que influenciam de forma direta no formato educacional desse público da Educação Especial ${ }^{4}$. Também, existe a preocupação da temática ser pouco explorada no meio docente em todas as áreas e níveis de ensino $^{6}$. Vale mencionar que, apesar das pessoas com Dotação e Talento serem geralmente identificadas nas áreas acadêmicas, é necessário evidenciar que existem muitas outras em que eles apresentam alto potencial e uma delas é a área psicomotora. Desse modo, é imprescindível que o professor de Educação Física esteja preparado para indicar e atender o alunado com especificidades e potencializá-lo.

Neste sentido, o referencial para este estudo respalda-se no Modelo Diferenciado de Dotação e Talento (DMGT) ${ }^{7}$. Para ele, as aptidóes cognitivas, do ponto de vista genético e biológico, atuam como blocos de construção das numerosas competências acadêmicas adquiridas na educação formal. Tratase de um processo contínuo e modulado por dois grandes conjuntos de influências, são eles: os catalizadores intrapessoais: caráter, personalidade, necessidades e desejos do indivíduo e os catalizadores ambientais proporcionados pelo meio - família, escola e ambiente social.

Dotação e Talento são conceitos distintos. A Dotação é a capacidade natural (raízes genéticas) e compóe-se de um total de $10 \%$ das pessoas. Já o Talento é estimulado pelos catalizadores (intrapessoal e ambiental) pela interação sociedade, escola, família, entre outras. Ainda sobre o Talento, os catalizadores terão função desenvolvedora da pessoa, ou seja, ela precisa ter oportunidades e contato com a sua área 
de maior potencial e interesse para se desenvolver ${ }^{7}$. Assim, "para desenvolver um talento é necessário haver dotação, mas a dotação como predisposição prevista no plano genético, pode não ser desenvolvida em talentos por falta de condiçôes no ambiente" ${ }^{\text {". }}$. Por esse motivo o modelo separa os conceitos de dotaçấo, potencial, aptidão e habilidades naturais 7 . Para tanto, autoras 9 assinalam que a capacidade natural, ou seja, aquela própria do indivíduo, é definida como aptidão. No que diz respeito a competências adquiridas, seja por treino, aprendizagem intencional ou ensino denomina-se desempenho. A FIGURA 1 ilustra o Modelo7.

Fonte: GAGNE?

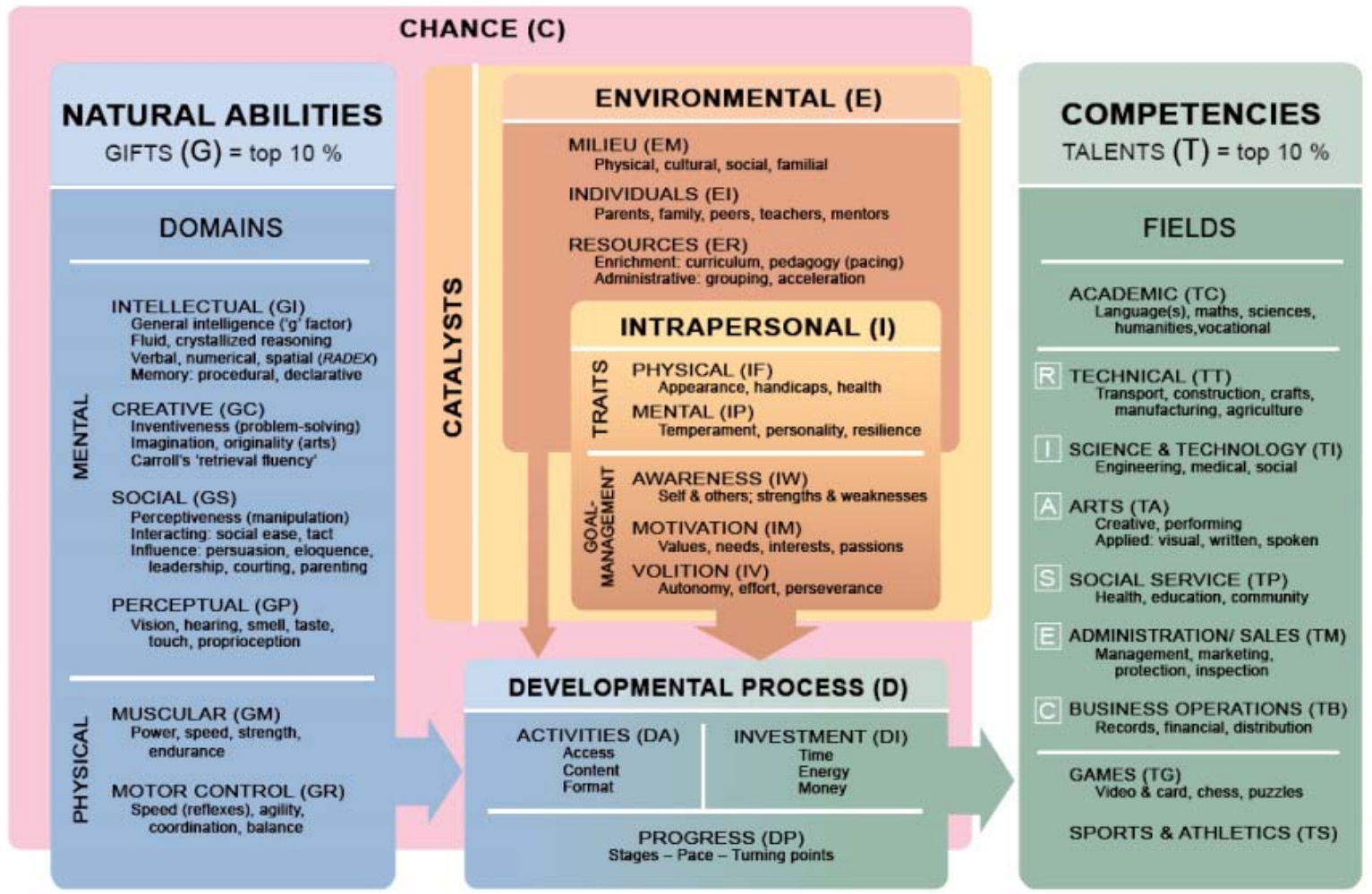

FIGURA 1 - Gagné's Differentiated Model of Giftedness and Talent (DMGT).

O DMGT constitui uma representação comportamental das inúmeras influências, facilitando ou interrompendo o crescimento de competências em geral. Nele, o talento esportivo, foco deste estudo, é uma de suas manifestaçóes, pois, desempenha papel significativo no grande conjunto de influências das habilidades físicas naturais na junção com competências "treináveis" dadas pelo processo desenvolvimentista proporcionado pelo ambiente.

No que diz respeito ao domínio físico, de acordo com o DMGT, uma autora ${ }^{8}$ ressalta que em pessoas dotadas e talentosas:

[...]A Capacidade Física é facilmente reconhecível em comportamentos e açóes e dá origem a pelo menos três vias específicas de expressão: capacidade sensorial (visual, auditiva, olfativa...); capacidade motora, (força, equilíbrio, ritmo, resistência, precisão de reflexos); combinaçóes sensório-motoras, (coordenação viso-motor, auditivo-motora,...)

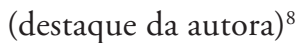

No que se refere à Educação Infantil, autoras ${ }^{6}$ mencionam a importância de se identificar as potencialidades desde tenra idade e, para isso, é imperiosa a formação de educadores, compreendendo toda a equipe escolar. Também, no campo da Educaçáo Física, entende-se que os professores escolares são capazes de detectar potenciais nas crianças desde a Educação Infantil ${ }^{10}$, buscando desenvolvê-los e encaminhá-los para atendimentos adequados, seja na própria escola ou centros esportivos.

A partir desses apontamentos tem-se como questão de pesquisa: $\mathrm{O}$ que há de estudos sobre dotação física e talento esportivo na Educação Infantil?

O objetivo é verificar se há pesquisas sobre dotação e talento na Educação Física na Educação Infantil. 


\section{Método}

A fim de responder a questão de pesquisa, recorreuse ao estudo denominado pesquisa bibliográfica de natureza qualitativa. A Pesquisa Bibliográfica caracteriza-se por ser "[...]um apanhado geral sobre os principais trabalhos já realizados, revestidos de importância, por serem capazes de fornecer dados atuais e relevantes ao tema"11. Enquanto a Qualitativa fundamenta-se "[...]em compreender os fenômenos, explorando-os desde a perspectiva dos participantes em um ambiente natural e em relação com a seu contexto"'2.

O percurso de coleta de dados seguiu conforme exposto na FIGURA 2.

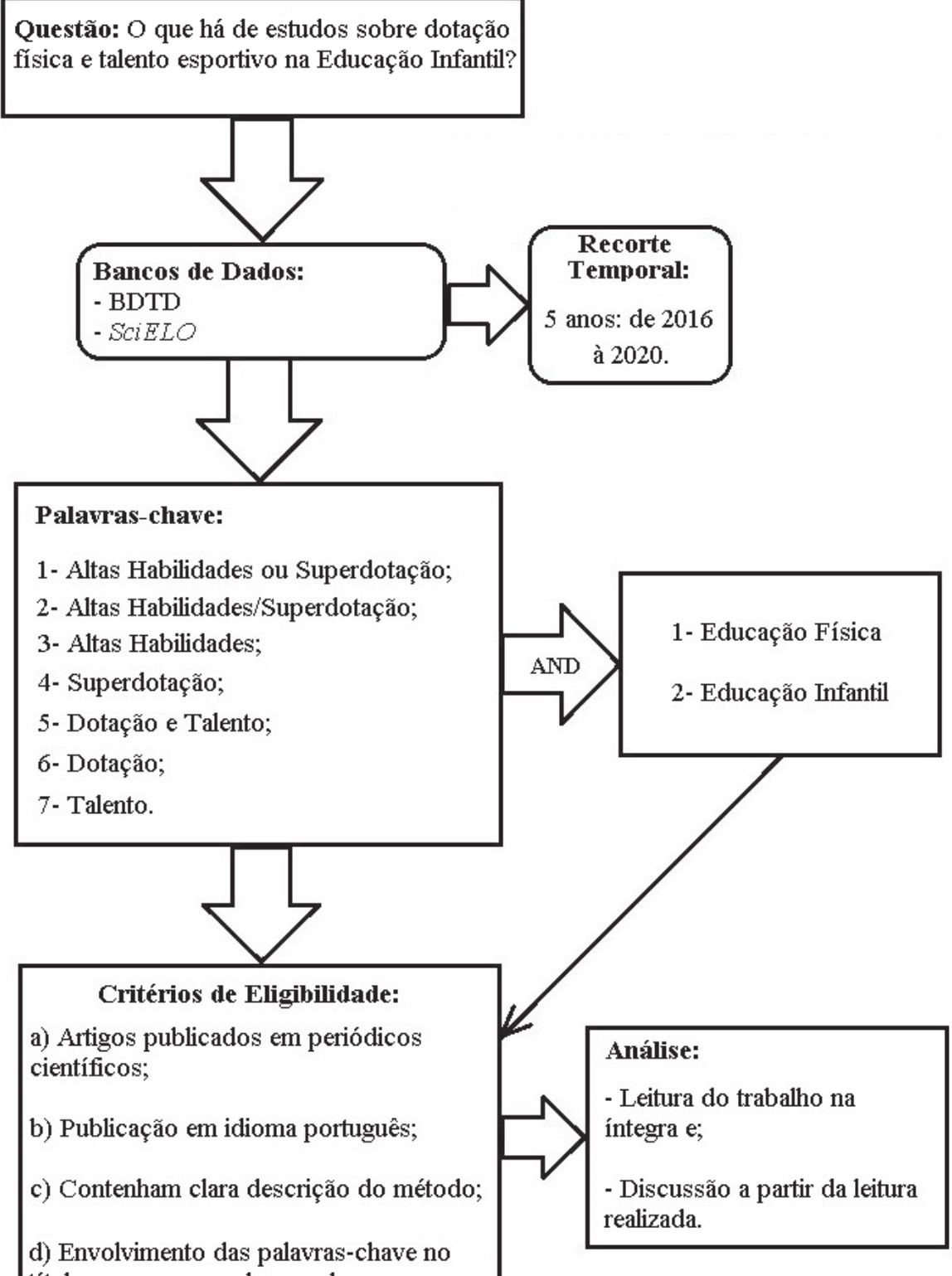

Fonte: Elaborado pelo autor.

título, resumo ou palavras-chave.

FIGURA 2 - Fluxograma do percurso da coleta de dados da pesquisa bibliográfica.

Foi realizado levantamento bibliográfico a fim de buscar estudos que versassem sobre o tema na interface Dotação e Talento e Educação Física na Educação Infantil em pesquisas no Brasil. As buscas ocorreram em dois bancos de dados nacionais sendo eles: Biblioteca Digital Brasileira de Teses e Dissertaçôes (BDTD) e Scientific Eletronic Library Online (SciELO-Brasil) com um recorte temporal 
de cinco anos. As palavras-chave buscadas foram: 1- Altas Habilidades ou Superdotação; 2- Altas Habilidades/Superdotação; 3- Superdotação; 4- Altas Habilidades; 5- Dotação e Talento; 6- Dotação e; 7- Talento; combinadas com: 1- Educação Física; 2- Educação Infantil.

Como critérios de elegibilidade para inclusão no estudo foram considerados: a) artigos, teses e dissertaçóes publicados em periódicos e banco de dados científicos; b) publicados no idioma

\section{Resultados}

$\mathrm{Na}$ BDTD foi encontrado um total de 123 (100\%) trabalhos sendo 101 dissertações $(82,11 \%)$ e $22(17,88 \%)$ teses. Os trabalhos irrelevantes para os critérios de inclusão e repetidos foram 106, representando $86,17 \%$. Já as produções relevantes em crivo de leitura de título resultaram em 17, representando $13,82 \%$. No segundo refinamento, resumo e palavras-chave (leitura de resumos e palavraschave), o resultado foi de 6 trabalhos, representando $4,87 \%$. O QUADRO 1 representa os trabalhos selecionados como relevantes. português; c) que contenham clara descrição do tema e método; d) que tivessem as palavras-chave no título, resumo ou palavras-chave. A delimitação de período foi dos últimos cinco anos (2016 a 2020). A partir disso, selecionaram-se: Título do Artigo (A) ou Dissertação (D) ou Tese (T); Autor(es)/a(as); Ano de defesa/Publicação; Área/ Universidade ou Revista e Assunto.

Os resultados obtidos foram analisados e organizados em quadros e tabelas.

As buscas na SciELO se basearam nos mesmos critérios bem como elegibilidade para inclusão com as mesmas palavras-chave, porém utilizando o operador booleano AND para otimizar a pesquisa com as palavras combinadas.

Nessas buscas houve um total de 11 artigos. Os trabalhos irrelevantes e repetidos foram 8 representando $72,72 \%$. Já as produçôes consideradas relevantes foram 3 , representando $27,27 \%$. No segundo refinamento (leitura de resumos e palavras-chave) obteve-se zero resultados. Não houve achados nos anos de 2016, 2018 e 2020.

QUADRO 1 - Dissertações e Teses - Biblioteca Digital Brasileira de Teses e Dissertações (2015 e 2020).

\begin{tabular}{|c|c|c|c|c|c|}
\hline No & $\begin{array}{c}\text { Título do Artigo(A) } \\
\text { ou Dissertação (D) } \\
\text { ou Tese (T) }\end{array}$ & Autor (es)/a (as) & $\begin{array}{c}\text { Ano de } \\
\text { defesa/ } \\
\text { Publicaçáo }\end{array}$ & $\begin{array}{c}\text { Área/ } \\
\text { Universidade } \\
\text { ou Revista }\end{array}$ & Assunto \\
\hline 01 & $\begin{array}{l}\text { Dotação física e } \\
\text { talento para esporte } \\
\text { em estudantes do } \\
\text { ensino fundamental: } \\
\text { análise de uma } \\
\text { proposta de } \\
\text { identificação } \\
\text { (T) }\end{array}$ & $\begin{array}{l}\text { Duarte, Emerson } \\
\text { Rodrigues; } \\
\text { Barbosa, Altemir José } \\
\text { Gonçalves. }\end{array}$ & 2017 & $\begin{array}{l}\text { Universidade } \\
\text { Federal de } \\
\text { Juiz de Fora } \\
\text { (UFJF) }\end{array}$ & $\begin{array}{l}\text { Discorre sobre } \\
\text { dotaçáo física e } \\
\text { talento esportivo, } \\
\text { baseado na Teoria de } \\
\text { Françoys Gagné. }\end{array}$ \\
\hline 02 & $\begin{array}{l}\text { Dotação física e } \\
\text { talento para natação: } \\
\text { análise de um } \\
\text { modelo teórico } \\
\text { (D) }\end{array}$ & $\begin{array}{l}\text { Ferreira, Clarissa Salles } \\
\text { Costa; } \\
\text { Barbosa, Altemir José } \\
\text { Gonçalves. }\end{array}$ & 2017 & $\begin{array}{l}\text { Universidade } \\
\text { Federal de } \\
\text { Juiz de Fora } \\
\text { (UFJF) }\end{array}$ & $\begin{array}{l}\text { Análise da dotação } \\
\text { física e talento } \\
\text { esportivo na } \\
\text { nataçáo a partir do } \\
\text { modelo teórico de } \\
\text { Françóys Gagné. }\end{array}$ \\
\hline
\end{tabular}

Continua 
QUADRO 1 - Dissertações e Teses - Biblioteca Digital Brasileira de Teses e Dissertações (2015 e 2020).

\begin{tabular}{|c|c|c|c|c|c|}
\hline No & $\begin{array}{c}\text { Título do Artigo(A) } \\
\text { ou Dissertaçáo (D) } \\
\text { ou Tese (T) }\end{array}$ & Autor (es)/a (as) & $\begin{array}{c}\text { Ano de } \\
\text { defesa/ } \\
\text { Publicaçáo }\end{array}$ & $\begin{array}{c}\text { Área/ } \\
\text { Universidade } \\
\text { ou Revista }\end{array}$ & Assunto \\
\hline 03 & $\begin{array}{l}\text { Seleção de talentos } \\
\text { esportivos sob a } \\
\text { ótica da revisão } \\
\text { sistemática } \\
\text { (D) }\end{array}$ & $\begin{array}{l}\text { Honda, Rogerio; } \\
\text { Massa, Marcelo. }\end{array}$ & 2019 & $\begin{array}{l}\text { Universidade } \\
\text { de São Paulo }\end{array}$ & $\begin{array}{l}\text { Revisão de } \\
\text { literatura sobre } \\
\text { talento esportivo na } \\
\text { Educação Física. }\end{array}$ \\
\hline 04 & $\begin{array}{l}\text { Talento esportivo: } \\
\text { uma revisão } \\
\text { sistemática } \\
\text { (D) }\end{array}$ & $\begin{array}{l}\text { Sá, Thiago Socio de; } \\
\text { Massa, Marcelo. }\end{array}$ & 2019 & $\begin{array}{l}\text { Universidade } \\
\text { de São Paulo }\end{array}$ & $\begin{array}{l}\text { Revisão de } \\
\text { literatura sobre } \\
\text { o conceito de } \\
\text { talento esportivo na } \\
\text { Educação Física. }\end{array}$ \\
\hline
\end{tabular}

Fonte: elaboração própria.

\section{Discussão}

A pesquisa encontrou 4 produçóes, sendo uma tese e três dissertaçóes defendidas nos anos de 2017 e 2019.

O primeiro deles é a tese "Dotação física e talento para esporte em estudantes do ensino fundamental: análise de uma proposta de identificação"13. $\mathrm{O}$ recorte teórico feito no primeiro capítulo traz várias contribuições de autores tanto das ciências do esporte como da Psicologia para explicar as diferentes controvérsias acerca do talento esportivo. Pautandose no $D M G T$, o autor ${ }^{13}$ traz evidências dos alunos com características de Dotação e Talento a partir de três estudos. De forma empírica, o autor propóe investigar e testar o Modelo Diferencial de Dotação e Talento (DGMT 2.0).

Ele observou que as produçóes têm um olhar enviesado para a dotação em jovens esportistas que praticam futebol, sendo estes do sexo masculino. Além disso, quando ressaltada a realidade brasileira, foi possível identificar precarização de trabalhos científicos nessa perspectiva. $\mathrm{O}$ autor ${ }^{13}$ partiu da avaliação de capacidades físicas em pessoas com dotação levando em consideração a manifestação da dotação nos diferentes sexos, idade, maturação e prática deliberada por meio de medidas antropométricas e de aptidão física com alunos do ensino fundamental. Além da diferenciação entre meninos e meninas, foi organizado dois tipos de dotação: Dotação Antropométrica (DA) e Dotação Motora (DM). O último estudo realizado pelo pesquisador ${ }^{13}$ teve como análise catalisadores ambientais e intrapessoais, processo de desenvolvimento e talento esportivo a partir de Modelos de Equação Estrutural (MEE) e DMGT 2.0. Testes antropométricos, questionários e testes de aptidão física foram realizados com alunos de escola pública do Ensino Fundamental. De modo geral, este estudo é muito relevante para a área e aponta estratégias para aplicabilidade e elementos elencados pelo próprio autor que se limitam pela complexidade dos modelos utilizados.

O segundo trabalho intitulado "Dotação física e talento para natação: análise de um modelo teórico" trata-se de uma dissertação defendida pela pesquisadora ${ }^{14}$ e propóe analisar um modelo diferencial de Dotação e Talento voltado para a modalidade natação baseando-se no $D M G T$ 2.0 , estabelecendo relaçóes com demais autores específicos da Educação Física. A autora ${ }^{14}$ realizou dois estudos: o primeiro deles analisou 
propriedades métricas de um único Protocolo de Identificação de Dotação Física para Natação (PIDOFINA) com nadadores.

No segundo, além de nadadores, participaram treinadores e foram utilizados um conjunto de medidas para análise de propriedades métricas para identificação de talento na natação a fim de analisar a relação dos perfis psicológicos e dotação física. Para tratamento dos dados houve um estudo quantitativo por estatística descritiva, a fim de mensurar desempenhos e identificar dotação física para natação. Ressalta que, as características antropométricas e morfológicas são importantes no rendimento da modalidade pela biomecânica que difere atletas de elite dos demais. O estudo está no campo das modalidades esportivas, o qual não é o foco da pesquisa proposta nesse artigo. Entretanto o estudo abrange possibilidades tanto de estabelecer relação com autores já conhecidos na Educação Física bem como possibilidade de conhecer instrumentos que podem ser atrelados ao DMGT $2.0^{7}$.

O título "Seleção de talentos esportivos sob a ótica da revisão sistemática" foi o terceiro trabalho e a segunda dissertação encontrada e foi defendida por um pesquisador ${ }^{15}$. Os objetivos da pesquisa foram "identificar o estado da arte dos trabalhos publicados" 15 e "[...] ajudar no direcionamento que as pesquisas sobre a temática podem tomar apontando as potencialidades e lacunas existentes" 15 . O estudo parte de metodologia de revisão sistemática de literatura em um recorte de oito anos. O trabalho traz contribuiçôes exclusivamente no campo do alto desempenho/rendimento de atletas de diferentes modalidades. A perspectiva perpassa pelo campo fisiológico e técnico bem como no campo da psicologia do esporte numa abordagem voltada para a esfera avaliativa em condicionamento físico, "performance" no esporte e treinamento esportivo. Além disso, em nenhum momento da pesquisa há menção a dotação e talento na perspectiva de teóricos na abordagem voltada para a Educação Especial. Eleger este trabalho para compor o levantamento serviu como exemplo para que possa ser evidenciado como a Dotação e Talento, sob a ótica do público da Educação Especial, precisa ser conhecida e evidenciada na Educação Física, sobretudo escolar.

A dissertação ${ }^{16}$ sobre "Talento esportivo: uma revisão sistemática" foi o último trabalho encontrado nesta busca. $\mathrm{O}$ autor traz também uma revisão sistemática de literatura de recorte de um biênio sob o olhar educacional e da aprendizagem com o objetivo de "a) Apresentar o estado da arte dos artigos que abordam o talento esportivo[...]. b) Sumarizar as principais caracteristicas, contribuiçôes e as modalidades esportivas mais abordadas[...]. c) Ajudar no desenho de futuros estudos, identificar potências e fragilidades sobre o Talento esportivo"16. Entretanto, o referencial teórico adotado pelo pesquisador ${ }^{16}$ está pautado no Modelo de Bloom, Modelo de Csikszentmihalyi e Modelo de Ericsson sob a ótica do rendimento e condicionamento físicos relacionados com a Fisiologia e a Psicologia. Conclui que se faz necessária a "[...]publicação e validaçáo de modelos experimentais nos processos de consolidação do talento, e a vasta gama de publicaçóes aparece de forma positiva quando de fato fomenta novidades na área da Educação Física [...]"' $]^{\text {' }}$. O autor abre discussão sobre a interdisciplinaridade entre os autores mais específicos da Educação Física com os autores da perspectiva da Dotação e Talento. Abordar esse estudo possibilita também interagir com a área da Educação Física, a fim de mostrar a dicotomia entre os termos, pois, o tema abordado no estudo ${ }^{16}$, talento esportivo, apesar de estabelecer uma relaçáo com a terminologia adotada neste artigo, ainda apresenta divergência em seu significado.

É perceptível que há escassez de pesquisas que abordem especificamente a dotação física e talento esportivo na Educação Física Escolar na Educação Infantil, pois, não foi encontrado nenhum trabalho neste nível de ensino. Verificou-se, também, que há falta de estudos que contemplem a perspectiva da Dotação e Talento voltados para o público da Educação Especial. As produçóes encontradas tratam de estudos sobre diferentes conceitos de Talento esportivo na Educação Física e em diferentes abordagens e perspectivas. Alguns não contemplam a Educação Física escolar e outros, quando a abordam, se referem a outros níveis de ensino. Verificou-se como limite da pesquisa que as buscas poderiam ser expandidas para outros bancos de dados.

Infere-se, que este estudo possa contribuir para interesses futuros sobre a temática, tendo em vista a baixa produção na interface Dotação e Talento com a Educação Física e a ausência na Educação Infantil. 


\begin{abstract}
Physical giftedness and sports talent: academic researches at kindergarten

The physical giftedness and the sports talent are manifested for playing a significant role in the great set of influences of the natural physical abilities united to the trainable competences by the environmental development process. The reference was the Gagné's Differentiated Model of Giftedness and Talent (DMGT). Thus, the general objective was to investigate the Giftedness and Talent and Physical Education interface in the Kindergarden. The methodology used was the bibliographic research and qualitative study. Academic productions were searched in two databases: Brazilian Digital Library of Thesis and Dissertations (BDTD) and Scientific Eletronic Library Online (SciELO), with a five-year time frame. The results obtained were four productions: one thesis and three master dissertations defended between 2017 and 2019. It is concluded that there is little research that specifically addresses to the physical gifted and sports talent at Kindergarden, and the found productions deal with other levels of education. This emphasizes the importance of looking at gifted and talented children since the beginning of the educational journey.
\end{abstract}

KEYS wORDS: Giftedness; Talent; Physical Education; Kindergarten.

\title{
Referências
}

1. Brasil. Ministério da Educação. Lei de Diretrizes e Bases da Educação Nacional. LDBEN 9.394, de 20 de dezembro de 1996. Disponível em: http://www.planalto.gov.br/ccivil_03/Leis/L9394.htm. Acesso em: 02 de nov 2020.

2. Brasil. Ministério da Educação. Conselho Nacional de Educação. Câmara de Educação Básica. Resolução no 4, de 02 de outubro de 2009. Resoluçáo No 4, de 2 de Outubro de 2009: Institui Diretrizes Operacionais para o Atendimento Educacional Especializado na Educação Básica, modalidade Educação Especial. Brasília, DF: Diário Oficial da União, 05 out 2009. Seçáo 1, p. 17-17. Disponível em: https://www.jusbrasil.com.br/diarios/897119/pg-17-secao-1-diario-oficial-da-uniao-doude-05-10-2009. Acesso em: 26 nov 2020.

3. Antipoff CA, Campos, RHF. Superdotação e seus mitos. Rev Sem Assoc Bras Psicol Escolar Educ. 2010;14(2):301-309. Disponível em: https://www.scielo.br/pdf/pee/v14n2/a12v14n2.pdf. Acesso em: 2 nov 2020.

4. Brasil. Ministério da Educação. Secretaria de Modalidades Especializadas de Educação. Política Nacional de Educação Especial: equitativa, inclusiva e com aprendizado ao longo da vida. Secretaria de Modalidades Especializadas de Educação. Brasília; MEC. SEMESP. 2020. 124 p. Disponível em: https://www.gov.br/mec/pt-br/mec-lanca-documento-sobre-implementacaoda-pnee-1/pnee-2020.pdf. Acesso em: 28 de nov 2020.

5. Pérez SGB, Freitas SN. Manual de identificação de altas habilidades/superdotação. Guarapuava: Apphendere, 2012. 121 p.

6. Braz PP, Rangni RA. Conhecimento de gestores da educação infantil sobre aceleração para alunos com altas habilidades/ superdotaçâo. Rev Online Política Gestáo Educ. 2019;23(3). Disponível em: https://periodicos.fclar.unesp.br/rpge/article/ view/12645. Acesso em: 3 jan 2021.

7. Gagne F. From genes to talent. Rev Educ. 2015;368:12-37. Disponível em: http://www.educacionyfp.gob.es/dctm/revista-deeducacion/articulosingles/gagne.-f.-en.-1-368.pdf?documentId=0901e72b81cbf793. Acesso em: 4 nov 2020.

8. Guenther ZC. Alunos dotados e talentosos na escola: não podem esperar mais. Sobredotação. 2011;12(1):5067. Disponível em: https://www.aneis.org/wp-content/uploads/2016/08/sobredotacao_v12-2011.pdf. Acesso em: $27 \mathrm{dez} 2020$.

9. Guenther ZC, Rondini CA. Capacidade, dotação, talento, habilidades: uma sondagem da conceituação pelo ideário dos educadores. Educ Rev. 2012;28(1):237-266. Disponível em: https://repositorio.unesp.br/bitstream/handle/11449/28889/ S0102-46982012000100011.pdf?sequence=1\&isAllowed=y. Acesso em: 27 dez 2020.

10. Ferraz OL, Flores KZ. Educação física na educação infantil: influência de um programa na aprendizagem e desenvolvimento de conteúdos conceituais e procedimentais. Rev Bras Educ Fís Esporte. 2004;18(1). Disponível em: http://www.revistas.usp. br/rbefe/article/view/16550. Acesso em: 3 jan 2021.

11. Marconi MA, Lakatos EM. Fundamentos da Metodologia Científica. 5. ed. São Paulo: Atlas, 2003. 311 p.

12. Sampieri RH et al. Metodología de la investigación. 6. ed. México: McGraw-Hill / Interamericana Editores, 2014. 634 p. 
13. Duarte ER. Dotação física e talento para esporte em estudantes do ensino fundamental: análise de uma proposta de identificação. 2017. 96 f. Tese (Doutorado) - Curso de Programa de Pós-Graduação em Psicologia, Psicologia, Universidade Federal de Juiz de Fora, Juiz de Fora, 2017. Cap. 5. Disponível em: https://repositorio.ufff.br/jspui/handle/uff/5591. Acesso em: 10 dez 2020.

14. Ferreira CSC. Dotação física e talento para natação: análise de um modelo teórico. 2017. 87 f. Dissertaçáa (Mestrado) - Curso de Programa de Pós-Graduação em Psicologia, Psicologia, Universidade Federal de Juiz de Fora, Juíz de Fora, 2017. Cap. 3. Disponível em: https://repositorio.uff.br/jspui/handle/uff/5660. Acesso em: 10 dez 2020.

15. Honda R. Seleção de talentos esportivos sob a ótica da revisão sistemática. 2019. 39 f. Dissertaçáo (Mestrado) - Curso de Programa de Pós-Graduação em Ciências da Atividade Física, Escola de Artes, Ciências e Humanidades, Universidade de São Paulo, São Paulo, 2019. Cap. 5. Disponível em: https://www.teses.usp.br/teses/disponiveis/100/100139/tde-04022020234249/publico/Mestrado_Rogerio_Honda_Final.pdf. Acesso em: 10 dez 2020.

16. Sá TS. Talento esportivo: uma revisão sistemática. 2019. 107 f. Dissertação (Mestrado) - Curso de Programa de Pós-Graduação em Ciências da Atividade Física, Escola de Artes, Ciências e Humanidades, Universidade de São Paulo, São Paulo, 2019. Cap. 3. Disponível em: https://teses.usp.br/teses/disponiveis/100/100139/tde-20082019-094551/publico/Thiago_Socio_de_Sa_ Versao_Corrigida.pdf. Acesso em: $10 \mathrm{dez} 2020$.

\begin{tabular}{r|r} 
ENDEREÇO & \\
Carlos Samuel Rossi & \\
Universidade Federal de São Carlos & Recebido: 04/01/2021 \\
Rodovia Washington Luiz, km 235 & Aceito: 06/01/2021 \\
São Carlos - SP - Brasil & \\
carlossamuelrossi.unesp@gmail.com & \\
lossamuelrossi@estudante.ufscar.br &
\end{tabular}

